\title{
Propuesta Integradora para un Estudio del Uso de Plantas con Propiedades Psicoactivas en Pipas del Período Alfarero Temprano y sus Implicancias Sociales.
}

\author{
Integrative Proposal for the Study of the Use of Plants with \\ Psychoactive Properties in Ceramic Pipes on the Early Ceramic \\ Period and its Social Implications
}

María Teresa Planella O. , Carolina Belmar P." Luciana Quiroz L. "II Y Daniela Estévez G. ${ }^{\text {IV }}$

\begin{abstract}
RESUMEN
Este trabajo es una nueva aproximación integral al estudio de pipas prehispánicas, incorporando la indagación de los aspectos sociales involucrados en el acto de fumar, y la selección de plantas utilizadas para esa finalidad, a través de la recopilación de información indirecta y directa. Se consultaron fuentes etnohistóricas y etnográficas que aportan al tema, y se aplicaron técnicas de recuperación y análisis de microfósiles contenidos en residuos adheridos de pipas procedentes de sitios arqueológicos del norte semiárido, zona central y sur de Chile. La cadena social operativa que se desarrolla en los diversos procesos que confluyen en la acción de fumar, es parte importante de este estudio, así como lo es llegar a conclusiones más amplias al proponer un nuevo enfoque para entender la definición de Complejos Fumatorios.

Los primeros resultados obtenidos avalan la dirección positiva del estudio realizado, con la observación de residuos diferenciales en los hornillos y los tubos/boquillas (depositación cultural) y los sedimentos (depositación natural). A su vez se discriminan diversas categorías de microfósiles, y se destaca la presencia de almidones cuyas caracteristicas pueden atribuirse a Nicotiana spp. Como parte de la propuesta, la secuencia de contenidos sociales vinculados a la acción de fumar, es explicada y graficada en un modelo operacional.

Palabras claves: Pipas, Microfósiles, Complejo Fumatorio, Periodo Alfarero Temprano.

\footnotetext{
Sociedad Chilena de Arqueología. El Amacai 505, Las Condes, Santiago, Chile. Correo-e: mtplanella@ gmail.com.

ii Universidad Internacional SEK. Arrieta 1000, Peñalolén, Santiago, Chile. Correo-e: carolina_belmar@hotmail.com.

iii Universidad de Chile. Lota 2538 Dpto. 22, Providencia. Correo-e:lucianaquiroz@hotmail.com.

iv Santa Elena 875, Santiago, Chile. Correo-e: estevez.grimberg@gmail.com.

Recibido: Septiembre 2011 Revisado: Enero 2012 Aceptado: Marzo 2012
} 


\section{Abstract}

This is a new comprehensive approximation to the study of the act of smoking, incorporating the investigation of the social aspects of smoking and the selection of plants through the collection of direct and indirect information. Ethnohistoric and ethnographic documents were consulted, and we obtained direct evidence through the application of recovery techniques and the analysis of microfossils contained in the residues found in pipes from archaeological sites in the northern semi-arid, central and southern Chile. Furthermore, the social operational chain involved in the action of smoking is an important part of this study, as is reaching wider conclusions, reason for which a new approach has been proposed with the object of understanding the definition of Smoking Complex.

The preliminary results support this study, with the observation of the differential depositation in the chambers and pipes/mouthpieces (cultural depositation) and sediment (natural depositation). In turn, the study differentiates various categories of microfossils and highlights the presence of starches with characteristics that may be attributed to Nicotiana spp. As a part of this proposal, the sequence of social contents linked to the act of smoking is explained and graphically shownas an operational model.Diccionario

Keywords: Smoking pipes, Microfossils, Smoking Complex, Early Ceramic Period.

\section{INTRODUCCIÓN}

Al igual que en otras áreas del conocimiento antropológico, hay aspectos del comportamiento humano que no han sido suficientemente explicados. Uno de estos aspectos dice relación con la dimensión ceremonial que envuelve en menor o mayor grado a las actividades de las sociedades del pasado, y que agrega un sentido extra empírico a tradiciones que son trasmitidas de generación en generación. Acceder al lenguaje secreto u oculto, como señala Eliade (1960), entender el sentido de lo explícito, y de los medios sensibles utilizados para generar una comunicación con la esfera sobrenatural (Föerster y Gundermann, 1996), el por qué se utilizan repetitivamente ciertos instrumentos y no otros en los ritos y ceremonias, son parte de las limitantes y a la vez estímulos que se presentan al investigador en su esfuerzo por reconstruir los contextos en que se manifiestan estos comportamientos.

En Chile, a partir de los cronistas de la época de Conquista y Colonia, surge información sobre las poblaciones originarias, que permite acceder a ciertas prácticas de naturaleza ceremonial o ritual. Se habla de juntas de indios (Vivar 1979 [1558], Ovalle 1969 [1646], Valdivia 1960 [1545]) 
de rritios y cerimonias introducidos por los yngas (Vivar 1979 [1558]: 37) pero, salvo algunas acotaciones en Vivar sobre fiestas, ritos funerarios y actuación de hechiceros, las descripciones de ceremonias no se detienen en particularidades, son muy reducidas y desde una óptica parcial y tangencial. En el siglo XVIII, los escritos de algunos naturalistas como J. I. Molina (2000 [1788]) demuestran un interés por detallar los procedimientos relacionados a ese tipo de prácticas y su entorno socio cultural. Es en este medio, en que se aprecia un cambio en las mentalidades de los observadores, que por primera vez registran las costumbres de utilizar el humo de tabaco en ceremoniales. Núñez de Pineda y Bascuñán (1984[1663]), Rosales (18771878) y posteriormente Medina (1898), relatan el uso de tabaco en la acción de fumar pipas, expeler y esparcir el humo como parte de rituales en las comunidades del sur, dando un claro protagonismo a esta planta, la que continuará siendo mencionada por otros autores para los mismos fines.

Desde los inicios del siglo XX se amplían los estudios sobre los aspectos de organización social relacionados con ritos y ceremoniales practicados por los pueblos originarios. Guevara (1911) encabeza esta orientación aportando contenidos muy detallados sobre contextos de uso del tabaco, seguido entre otros por Guevara y Oyarzún (1912), Gusinde (1917), Latcham (1924,1936), Housse (1940), Cooper (1949), Hilger (1957) Faron (1964), Wilbert (1987), Foerster (1995:95), Foerster y Gundermann (1996), en que se mencionan ceremonias de sanación o machitun y de rogativas o nguillatun. Se menciona el tabaco, Nicotiana spp. ${ }^{1}$, puchrem (Erize 1987) o pütrem (Serrano 1934), prácticamente como único material vegetal con significación ritual utilizado en la acción de fumar, y algunos componentes aromatizantes (Guevara y Oyarzún 1912, Latcham 1936), y a su vez las pipas o cachimbas quichra, quitraocütra (Latcham 1936) como elementos indispensables en dichas ocasiones, utilizados en el espacio ritual (Faron 1961) por los actores u oficiantes que las dirigen. Guevara y Oyarzún (1912) incluyen la acción de fumar como costumbre lúdica en contextos familiares, lo que según Latcham (1936:110) estaría representado "en el gran número de pipas antiguas halladas en las sepulturas".

La actividad de fumar, inhalar, y otras formas de utilizar distintas sustancias con compuestos psicoactivos, se encuentra ampliamente difundida entre los pueblos originarios de norte, centro y suramérica (Haberman 1984,Wilbert 1987,Schultes y Hoffman 1979,Dougherty 1972,Lagiglia 1992, Pérez Gollán y Gordillo 1994). Las características y uso de estas sustancias, llamadas también "visionarias", ha sido detallada para el norte de Chile entre otros autores por Torres (1998, 2001), Berenguer (2001), 
Hermosilla (2001), Llagostera (2001) y Chacama (2001); para la zona central por Planella et al. (2005-2006) y para la región sur por Citarella et al. (1995), Aldunate (2002-2003) y Olivos (2004).

Producto de excavaciones arqueológicas y revisión de colecciones, se constata que la costumbre de fumar ha estado inserta en la tradición cultural de poblaciones prehispánicas desde el período alfarero temprano (Cornely 1966, Niemeyer et al. 1989, 1998; Westfall 1993-94, Planella et al. 2000, Falabella et al. 2001, Reyes et al. 2003, 2004; Quiroz y Sánchez 2005). Recientes hallazgos de pipas en el norte semiárido, centro y sur de Chile han revitalizado y dado un nuevo impulso al estudio del importante tema de la existencia de contextos fumatorios e interesantes aspectos de ritualidad. Ello ha llevado a reflexionar acerca de qué tipo de plantas, ya sea con o sin compuestos psicoactivos, eran seleccionadas y utilizadas como contenidos de las pipas en distintos eventos sociales y rituales de las comunidades originarias, planteamiento que seapreciaa su vezen estudios trasandinos (FernándezDistel 1980, Fernández Distel et al. 1999, Capparelli et al. 2006, Andreoni 2010).

Luego del hallazgo de una importante cantidad de fragmentos de pipas en el sitio La Granja, al oeste de Rancagua en la zona central, se efectuó una primera aproximación directa a los componentes químicos depositados al interior de las pipas, cuyos resultados mostraron la presencia de alcaloides sin determinar la planta o plantas de origen (Falabella et al. 2001, Hairfield y Hairfield 2002, Muñoz y Peña 2009).A través de estos análisis químicos, se constató el uso de sustancias psicoactivas por parte de poblaciones Llolleo, del período Alfarero Temprano, que ocuparon el lugar aproximadamente entre los años 500 y 1000 d.C., lo que junto a otros indicadores llevó a considerar para dicho sitio la existencia de un "Complejo Fumatorio" (Planella et al. 2000, Falabella et al. 2001).

En forma reciente se ha desarrollado el análisis de residuos adheridos, que ha resultado una valiosa herramienta para determinar qué recursos, vegetales u otros, están asociados a los artefactos y definir su funcionalidad (Briuer 1976, Fullagar et al. 1996, Barton et al. 1998, Kealhofer et al. 1999, Rots etal. 2004, Babot et al. 2008). Los análisis de microfósiles y cromatografía de gases han sido algunas de las herramientas usadas exitosamente para este fin (Barton et al. 1998, Briuer 1976). El primero aborda esta tarea a través de la extracción e identificación de microvestigios vegetales y animales. El segundo lo logra mediante la separación de los residuos en sus componentes químicos utilizando el comportamiento, forma y peso molecular, y tipos de grupos funcionales para su identificación (Pollard et al. 2007). 


\section{Material y Método}

El material objeto de este estudio se compone de muestras de contenidos(residuos adheridos y sedimentos) de siete pipas de sitios de la Región Central (La Granja-Bypass Rancagua, Ciprés Consultores, 2002), dos de la región Sur (Villa JMC-01-Labranza, Temuco; Mera y Munita, 2008) y una del Norte semiárido (Pichicaven-Illapel- Troncoso, 2010) (Figura 1). Las diferencias de las cantidades de muestras (pipas), responde a la disponibilidad de ellas por la frecuencia en que fueron encontradas en cada sitio (Tabla 1).

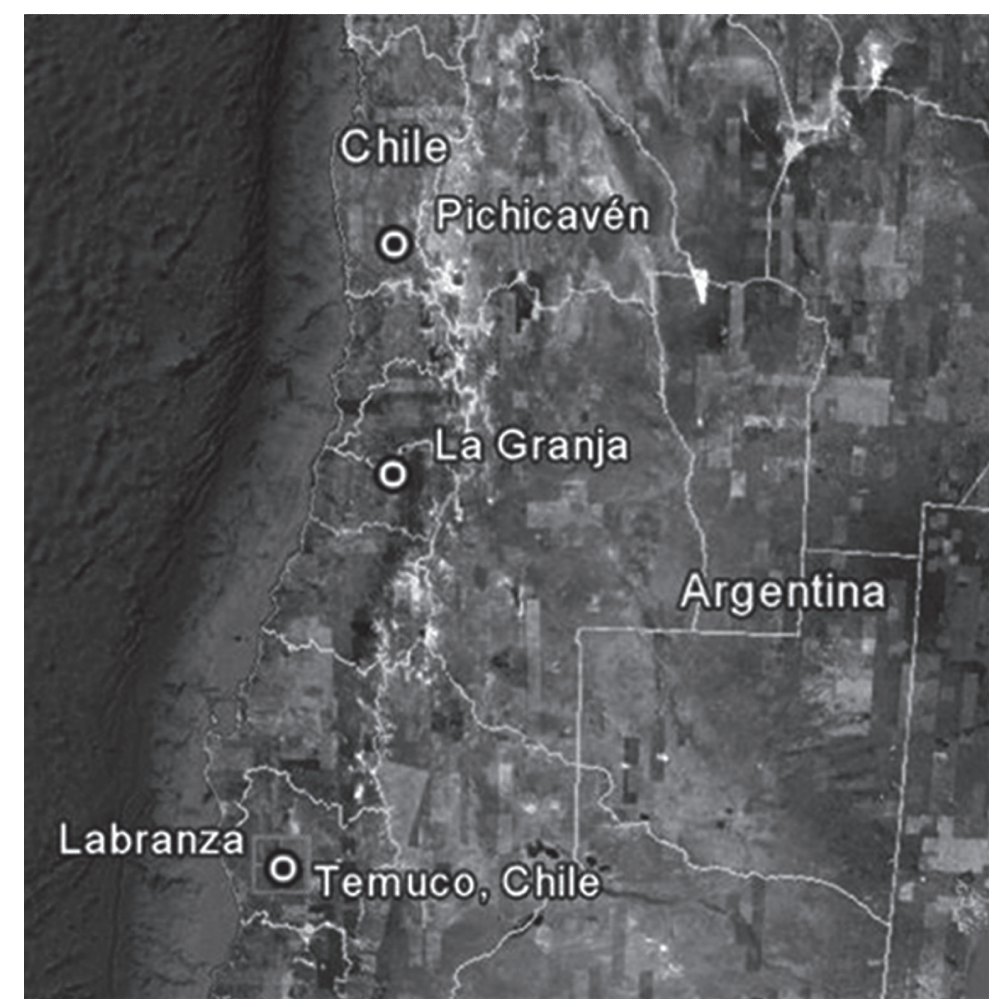

Figura 1: Mapa de ubicación de los sitios de procedencia de las pipas analizadas. Imagen extraida desde Google Earth

Figure 1: Sites localization map of the analyzed ceramic pipes. Image obtained from Google Earth.

Las siete primeras muestras corresponden al Complejo Cultural Llolleo fechado en La Granja en 500 a 1000 d.C. (Falabella et al. 2001), las dos siguientes se adjudican a la Cultura Pitrén datada en 890 a 1030 d.C. 
(Mera y Munita 2008), y la última al período Alfarero Temprano del Norte semiárido, cuenta con nueve fechas que fluctúan entre 530 a 1100 d.C. (Troncoso 2010). Las características tipológicas y morfológicas de las pipas analizadas varían de acuerdo a la procedencia regional y cultural (Figuras 2A-2I).

El estudio de microfósiles aplicado se plantea desde el análisis múltiple de microfósiles (Coilet al. 2003, Korstanje 2009) de sustancias adheridas en las pipas, que prioriza la recuperación e identificación del conjunto de microfósiles por sobre un único tipo. En consecuencia es necesario recurrir a una técnica menos agresiva, que permita la preservación del conjunto de microfósiles presentes en una muestra, en especial aquellos de naturaleza orgánica (Babot 2003, 2004; Kealhofer et al. 1999,Korstanje 2009). Para ello se propone utilizar el método de extracción directa de residuos (Loy 1994, Loyy Fullagar 2006: 197-198), que consiste en raspar las sustancias adheridas (hollín y otros) detectadas al interior de las pipas y montarlas en un porta-objeto con aceite de inmersión.

\begin{tabular}{|l|l|c|c|c|}
\hline Pipa & Profundidad & Hornillo & Tubo/Boquilla & Sedimento \\
\hline Pichicavén & $55-60 \mathrm{~cm}$ & $\mathrm{X}$ & $\mathrm{X}$ & $\mathrm{X}$ \\
\hline La Granja A121 & $0-30 \mathrm{~cm}$ & $\mathrm{X}$ & $\mathrm{X}$ & $\mathrm{X}$ \\
\hline La Granja A123 & $0-10 \mathrm{~cm}$ & $\mathrm{X}$ & $\mathrm{X}$ & $\mathrm{X}$ \\
\hline La Granja A124 & $40-50 \mathrm{~cm}$ & $\mathrm{X}$ & $\mathrm{X}$ & $\mathrm{X}$ \\
\hline La Granja A125 & $40-50 \mathrm{~cm}$ & $\mathrm{X}$ & $\mathrm{X}$ & $\mathrm{X}$ \\
\hline La Granja A127 & $40-50 \mathrm{~cm}$ & $\mathrm{X}$ & $\mathrm{X}$ & $\mathrm{X}$ \\
\hline La Granja A130 & $\sin$ nivel & $\mathrm{X}$ & $\mathrm{X}$ & $\mathrm{X}$ \\
\hline La Granja A131 & $0-20 \mathrm{~cm}$ & $\mathrm{X}$ & $\mathrm{X}$ & $\mathrm{X}$ \\
\hline Villa JMC1-A & $40 \mathrm{~cm}$ & $\mathrm{X}$ & $\mathrm{X}$ & \\
\hline Villa JMC1-B & $\sin$ contexto & $\mathrm{X}$ & $\mathrm{X}$ & \\
\hline
\end{tabular}

Tabla 1: Partes muestreadas de las pipas analizadas para estudio de microfósiles de los residuos adheridos.

Table 1: Sampled parts of ceramic pipes for microfossil analysis of residues. 

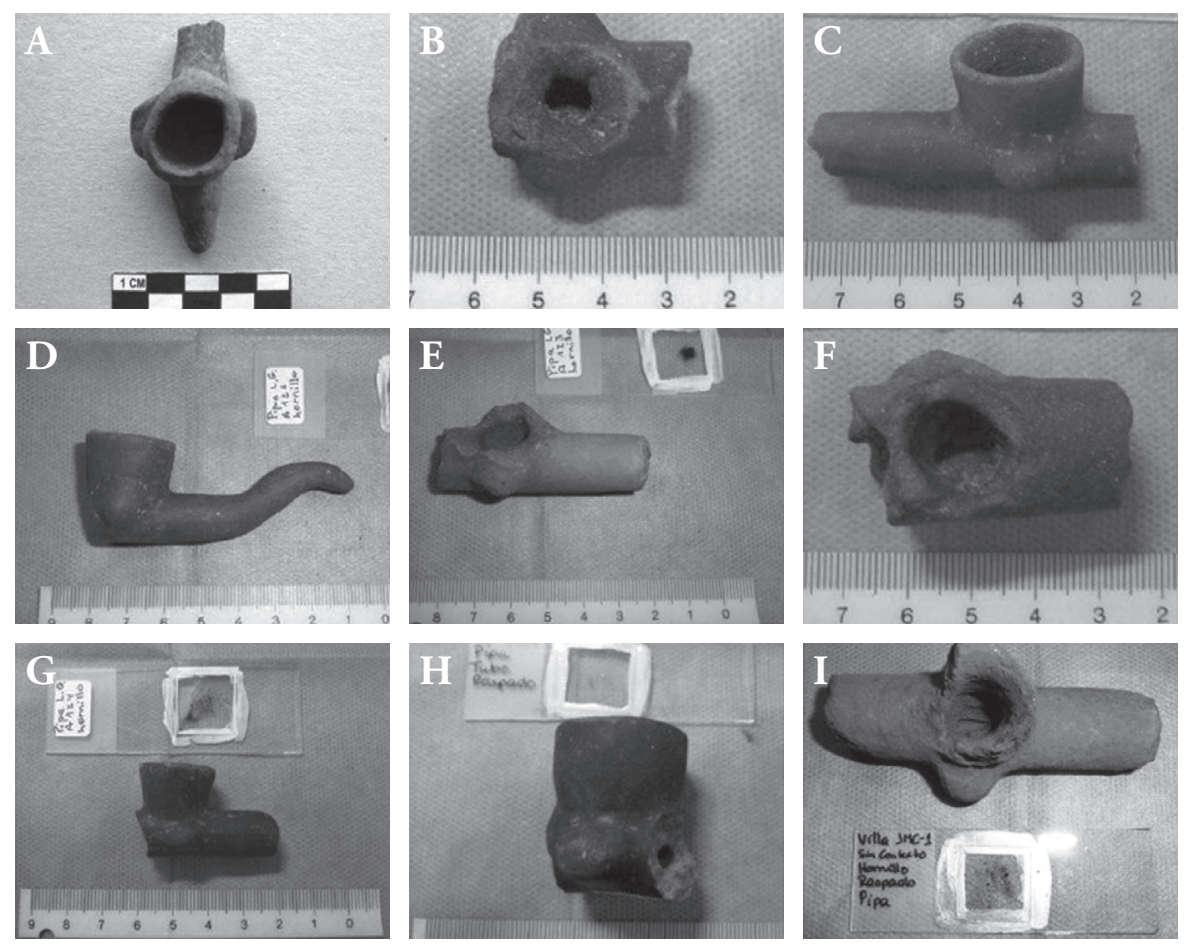

Figura 2: A a I: Pipas analizadas. Superior, izquierda a derecha: A) Pichicavén, IV Región; B-H) La Granja, VI Región; I) Labranza, IX Región

Figure 2: A to I: Analyzed ceramic pipes. Upper lines, from left to right: A) Pichicavén, IVth Region; B-H) La Granja, VIth Region; I) Labranza, IXth Region.

Se extrajeron muestras del hornillo y de las boquillas/tubos en forma separada, con el fin de detectar alguna diferencia en el registro y el estado de sus contenidos, producto del proceso de carbonización relacionado con el acto de fumar. A su vez, el relleno de sedimento de los hornillos fue procesado siguiendo el protocolo para análisis múltiple de microfósiles mediante la flotación en líquido pesado (Ioduro de Zinc) (Coil et al. 2003, Korstanje 2009). En este caso de estudio, el análisis de los sedimentos sirve como una muestra de control que permite identificar el conjunto de microfósiles depositados de forma natural en el suelo y discriminar aquellos asociados culturalmente al contexto de uso. En forma preliminar y para los fines perseguidos, se optó por utilizar el criterio de presencia/ausencia de morfotipos sin efectuar su cuantificación, ya que se estimó que su número en estas muestras no alcanza un nivel de significancia estadísticamente relevante. 
La descripción morfológica y atributos de los fitolitos se basó en el "International Codefor Phytolith Nomenclature 1.0" generado por el ICPN Working Group (2005). Se identificaron, midieron, describieron y anotaron los atributos relevantes de los otros microfósiles (diatomea, almidón y oxalato de calcio), así como se efectuó un conteo para cumplir los fines de clasificación. En el caso de los almidones, se midieron las cruces de extinción de los granos, y se anotó la presencia de rasgos diagnósticos, como forma, tamaño, lamellas, fisura o cicatrices, birrefringencia. La identificación se realizó por comparación con publicaciones especializadas (Reichert 1913,Korstanje y Babot 2007).

El material microfósil fue contrastado con una colección de referencia de plantas potencialmente consumidas en las regiones centro y sur de Chile (Planella et al. 2009) y en el área surandina (Korstanje y Babot 2007). La selección de plantas se basó en la información etnohistórica, además de los datos netamente botánicos de la presencia de alcaloides existente en todo Chile sin centrarse en la flora específica de la zona de estudio (p.e. Piptadenia colubrina o vilca, Norte Grande). Se muestrearon diferentes partes de las plantas: flor, hoja, semilla y tallo, los cuales fueron sometidos a dry ashing (Parret al. 2001) además de la observación de cortes frescos de las plantas.

\section{Resultados DE ANÁlisis DE MiCROFÓSILES}

Los resultados se segregaron por la procedencia de la muestra: hornillo, boquilla/tubo y sedimento de relleno. En general, se observa abundancia de fitolitos por sobre los otros microfósiles (almidones, polen, cristales, etc.) en los tres tipos de muestras que se extrajeron (Tablas 2, 3 y 4). 


\begin{tabular}{|l|c|c|c|c|c|c|c|c|c|}
\hline \multirow{2}{*}{ Pipa } & \multicolumn{9}{|l|}{ MICROFÓSILES } \\
\cline { 2 - 11 } & Fitolito & Almidón & Polen & Cristal & Tejido & Carbón & Diatomea & Esferulita & Quiste \\
\hline Pichicavén & 57 & 5 & & & 5 & $\mathrm{x}$ & & & \\
\hline LG A121 & 13 & 1 & & & & $\mathrm{x}$ & & & \\
\hline LG A123 & 6 & & & & & $\mathrm{x}$ & & & \\
\hline LG A124 & 14 & & 1 & 2 & & $\mathrm{x}$ & & & \\
\hline LG A125 & 16 & & 1 & & & $\mathrm{x}$ & 1 & & \\
\hline LG A127 & 7 & 1 & & & & $\mathrm{x}$ & & & \\
\hline LG A130 & & 2 & & & & $\mathrm{x}$ & & & \\
\hline LG A131 & 17 & 1 & & & & $\mathrm{x}$ & & & \\
\hline JMC1 A & 24 & & & & & $\mathrm{x}$ & & & \\
\hline JMC1 B & 19 & 1 & & & 1 & $\mathrm{x}$ & & & \\
\hline TOTAL & $\mathbf{1 7 3}$ & $\mathbf{1 1}$ & $\mathbf{2}$ & $\mathbf{2}$ & $\mathbf{6}$ & & $\mathbf{1}$ & $\mathbf{0}$ & $\mathbf{0}$ \\
\hline
\end{tabular}

Tabla 2: Sintesis de resultados de los estudio de microfósiles. Detalle de cantidades según tipos de microfósiles recuperados del hornillo de las pipas analizadas.

Table 2: Result synthesis of microfossil analysis. Quantitative detail per microfossil types recovered from pipes chambers.

En el caso de los almidones (Figuras 3A-3I), se nota una alta frecuencia en el contenido de las boquillas/tubos $(\mathrm{n}=34)$ por sobre la de los hornillos ( $\mathrm{n}=11)$, posiblemente debido a la diferencia de temperatura producida por la combustión (Tablas 2, 3 y 4). Se registró un conjunto de almidones indeterminados que corresponden ya sea a almidones transitorios o redundantes; en otros no se ha encontrado su correlato en las colecciones de referencia (Figuras 3E-4H).La evidencia de procesos tafonómicos en los granos de almidónen general puede ser apreciada como fisuras, cicatrices, fracturas, pérdida de birrefringencia, entre otros (Babot 2003).En el caso de las pipas, los daños remiten al procesamiento de las plantas utilizadas, como puede ser el desecamiento, molienda, tostado y carbonización de los vegetales consumidos en el acto de fumar;y los dańos observados corresponden a la alteración del hilo (Figuras 3D y 3I), pérdida de birrefringencia (Figura 3D) y cicatrices. 


\begin{tabular}{|l|c|c|c|c|c|c|c|c|c|}
\hline \multirow{2}{*}{ Pipa } & \multicolumn{9}{|c|}{ MICROFÓSILES } \\
\cline { 2 - 11 } & Fitolito & Almidón & Polen & Cristal & Tejido & Carbón & Diatomea & Esferulita & Quiste \\
\hline Pichicavén & 6 & 3 & & & & X & & & \\
\hline LG A121 & 8 & & & & & X & & & \\
\hline LG A123 & 1 & 13 & & & 1 & X & & & \\
\hline LG A124 & 14 & 4 & & 1 & 1 & X & 1 & & \\
\hline LG A125 & 9 & 1 & & & 1 & X & & & \\
\hline LG A127 & 22 & & & & & X & & & \\
\hline LG A130 & 5 & 7 & & & & X & 1 & & \\
\hline LG A131 & 1 & & & 2 & & X & & & \\
\hline JMC1 A & 38 & 4 & & & & X & & & \\
\hline JMC1 B & 39 & 2 & & & & X & 1 & & \\
\hline TOTAL & $\mathbf{1 4 3}$ & $\mathbf{3 4}$ & $\mathbf{0}$ & $\mathbf{3}$ & $\mathbf{3}$ & & $\mathbf{3}$ & $\mathbf{0}$ & $\mathbf{0}$ \\
\hline
\end{tabular}

Tabla 3: Sintesis de resultados de los estudio de microfósiles. Detalle de cantidades según tipos de microfósiles recuperados del tubo y/o boquilla de las pipas analizadas. Table 3: Result synthesis of microfossil analysis. Quantitative detail per microfossil types recovered from mouthpieces and tubes.

\begin{tabular}{|l|c|c|c|c|c|c|c|c|c|}
\hline \multirow{2}{*}{ Pipa } & \multicolumn{9}{|l|}{ MICROFÓSILES } \\
\cline { 2 - 11 } & Fitolito & Almidón & Polen & Cristal & Tejido & Carbón & Diatomea & Esferulita & Quiste \\
\hline Pichicavén & 95 & & & 18 & 4 & & & & \\
\hline LG A121 & 5 & 1 & & 2 & & & & & \\
\hline LG A123 & 50 & 9 & 3 & & & & & & \\
\hline LGA124 & 59 & 6 & & 22 & 2 & & & & 1 \\
\hline LGA125 & 4 & 2 & & 2 & & & & 15 & \\
\hline LGA127 & 39 & 2 & 1 & & & 1 & & & 22 \\
\hline LGA 130 & 88 & & & & & & & & \\
\hline LGA 131 & & & 1 & & & & & & \\
\hline TOTAL & $\mathbf{3 4 0}$ & $\mathbf{2 0}$ & $\mathbf{5}$ & $\mathbf{4 4}$ & $\mathbf{6}$ & $\mathbf{1}$ & $\mathbf{0}$ & $\mathbf{1 5}$ & $\mathbf{2 3}$ \\
\hline
\end{tabular}

Tabla 4: Sintesis de resultados de los estudio de microfósiles. Detalle de cantidades según tipos de microfósiles recuperados del sedimento de relleno de las pipas analizadas.

Table 4: Result synthesis of microfossil analysis. Quantitative detail per microfossil types recovered from sediments. 

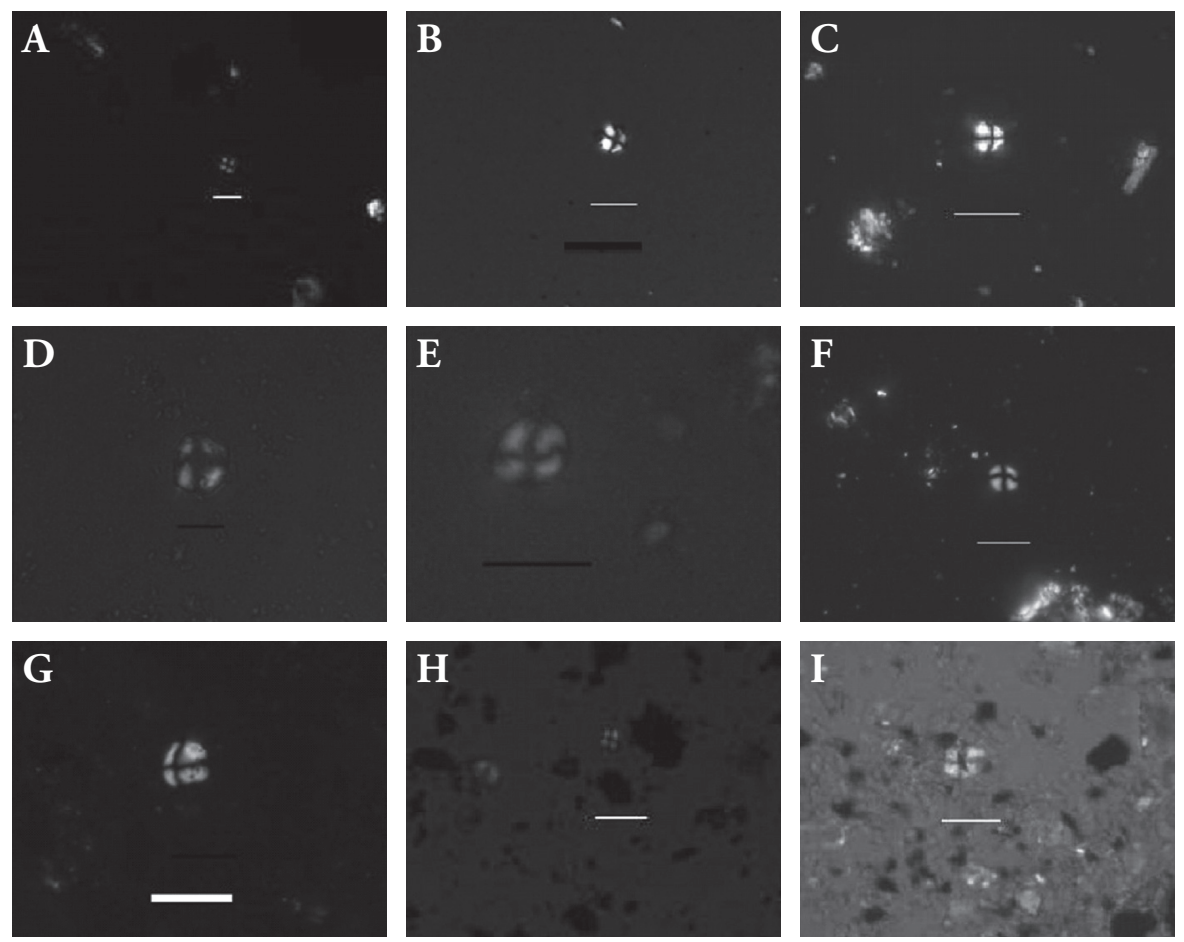

Figura 3: A a I: Granos de almidón recuperados de pipas. A) simil Nicotianaspp.,

B) simil Nicotianaspp. y C) simil Nicotianaspp. D) grano de almidón con

daño tafonómico, E) grano de almidón indeterminado y F) grano de almidón

indeterminado. G) grano de almidón indeterminado, H) grano de almidón indeterminado y I) grano de almidón con daño tafonómico de quemado. Escala de $20 \mu$.

Figure 3: A to I: Starch grains recovered from ceramic pipes. A) similNicotiana spp. , B) similNicotiana spp., C) similNicotiana spp., D) starch grain with taphonomic damage, E) Undetermined starch grain, F) Undetermined starch grain, G) Undetermined starch grain, H) Undetermined starch grain, I) Taphanomic burnt damaged starch grain. Scale $20 \mu$.

También es de interés la presencia de microcarbones en el contenido del hornillo (Figura 4G) y boquilla/tubo y su casi absoluta ausencia en el sedimento de relleno, lo que indica que se trata de residuos resultantes de la combustión de elementos en las pipas. A su vez se aprecia una cantidad notoria de fitolitos correspondientes a pastos (Figura $4 \mathrm{~A}$ y $4 \mathrm{E}$ ) y de cristales (Figura 4I) en los sedimentos de relleno, a diferencia de lo que acontece en hornillos y boquillas/tubos, lo que da cuenta de su carácter de depositación natural (Tabla 4). 


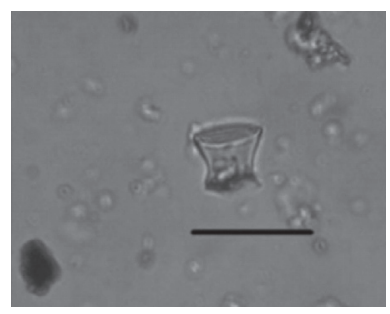

A) LG A 123, sedimento

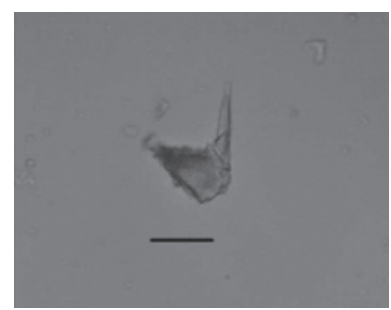

D) Pichicavén, hornillo

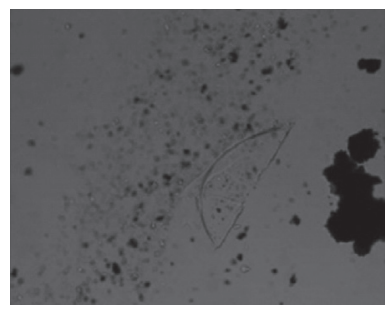

G) LG A 123, hornillo

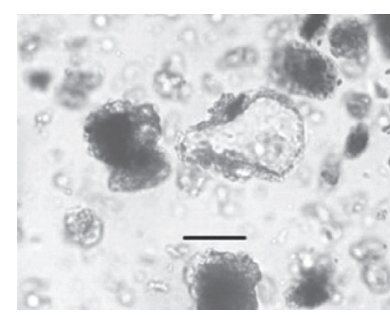

B) Labranza, boquilla

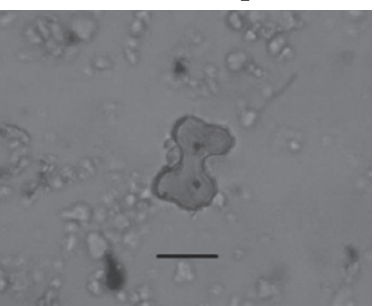

E) LG A 123, sedimento

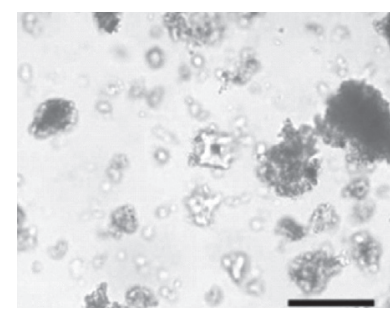

H) Labranza, boquilla

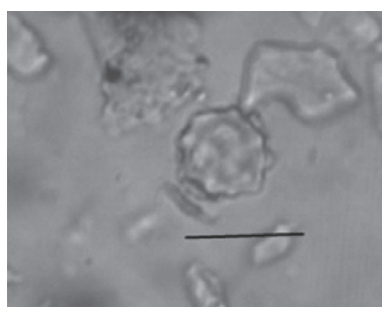

C) Pichicavén, sedimento

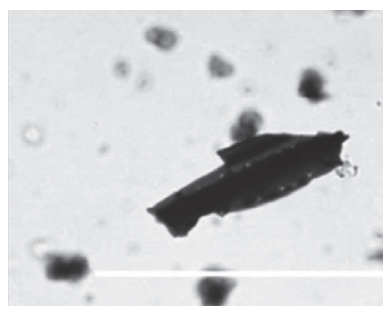

F) LG A 123, tubo

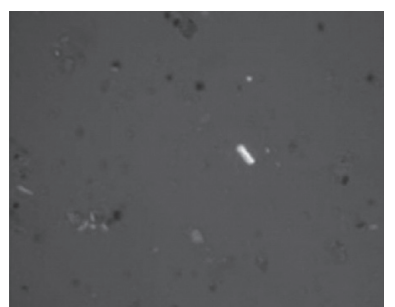

I) LG A 124, sedimento

Figura 4: A a I: Fitolitos recuperados de las pipas. A) Rondel de borde ondulado, B) Bulliforme, C) Fitolito globular espinado, D) Tricoma indeterminado E) Bilobulado y F) Tejido con puntuaciones, Dicotiledónea, G) Microcarbones, H) Silicofitolito paralelepipedo simi lBambusoidea y I) Cristal.Escala $20 \mu$.

Figure 4: A to I:Phytolihs recovered from pipes. A) Rondel with wavy rim, B) Bulliforme C) Globular spinney phytolith. D) Undeterminedtricoma, E) Bilobulated, F) Dotted tissue, Dicotyledone, G) Microcarbons, H) parallelepiped phytolith similBambusoidea y I) Cristal.Scale $20 \mu$.

En el caso del residuo de la pipa procedente de Pichicavén, se registró un fitolito correspondiente a una porción de pelo o tricoma, el cual se asemeja a lo registrado para hoja de Nicotiana spp., sin embargo, al tratarse de un fragmento tan pequeño es difícil asignarlo con seguridad a este género. También se registraron una serie de células cortas articuladasy un tricoma indeterminado (Figura 4D) que se asemeja a las estructuras asociadas a las hojas y tallos en general. Además, en el hornillo, se recuperaron restos de tejidos carbonizados que presentan puntuaciones, adscribibles a las Dicotiledóneas $^{2}$ (Figura 4F). En el sedimento de relleno se destaca un fitolito globular con ornamentación asimilable a Arecaceae (Figura 4C). 
Los residuos analizados de las pipas de Villa JMC-1 Labranza indican la presencia de gramíneas a través de la identificación de morfotipos de esta familia. El registro de células bulliformes (Figura 4B) y parenquimáticas, se refiere al posible uso de hojas y tallos. También se observó un grano de almidón, y un tricoma (Figura 5A), además de silico fitolitos conformados por un conjunto de células parenquimáticas (Figura $5 \mathrm{C}$ ), todo lo anterior asimilable a Nicotianaspp. (Figura 5D y Nicotiana acuminata, Figura 5B) (Quiroz et al. 2011). Es sugerente la identificación de un almidón de Solanum spp., que refrendaría el dato etnográfico del uso de hojas de papa a modo de sustituto de tabaco (Guevara 1911).

Un dato de suma relevancia que enfatiza las resultados que vinculan la información etnográfica y nuestro estudio, es la observación reiterada de almidones asimilables al género Nicotiana spp. (Korstanje y Babot 2007) en dos tubos/boquillas de pipas de La Granja Bypass Rancagua (LGA 123 y LGA 127, Figuras 3A y 3B), en el hornillo de la pipa de Pichicavén (Figura 3C) y en la pipa sin contexto de JMC1-Labranza ${ }^{3}$.

\section{IMPLICANCIAS SOCIALES}

\section{Modelo explicativo y cadena operativa}

Desde sus inicios, la disciplina arqueobotánica se ha propuesto interpretar la composición del registro de las especies presentes en los contextos arqueológicos, desde la perspectiva de la producción y en segunda instancia del procesamiento de los recursos vegetales. En los años setenta con la aplicación de la técnica de flotación, Dennell (1976) propone un modelo predictivo que explique las asociaciones de especies, su estado de conservación e integridad de los especímenes, de acuerdo a un contexto específico y etapa de procesamiento. Sobre esta base, otros investigadores han manifestado la necesidad de respaldar dicho modelo explicativo desde la observación etnográfica, analizando cuantitativa y cualitativamente las transformaciones experimentadas por los recursos involucrados en las etapas o actividades de procesamiento, y de esta manera compararlas con el registro arqueológico (Harris y Hillman1989). En forma similar, Harstof (1988) ratifica que la composición específica, anatómica y tafonómica del registro arqueobotánico varía en función de la secuencia de uso de los recursos alimenticios y sus contextos, ordenándola en las etapas de producción, procesamiento y consumo. Destaca que la pesquisa de estos ámbitos de actividades en el registro, requiere estrategias 
técnicas y analíticas diferenciadas orientadas a recuperar evidencias directas de ellas, ya que señala que la etapa de consumo es mayormente inferida a partir de evidencia indirecta (presencia de artefactos relacionados al consumo, porciones no consumidas de los recursos, evidencia isotópica bioarqueológica).

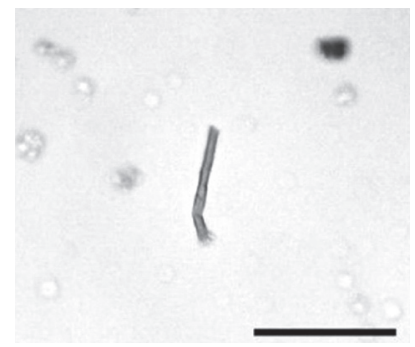

A) Tricoma Labranza

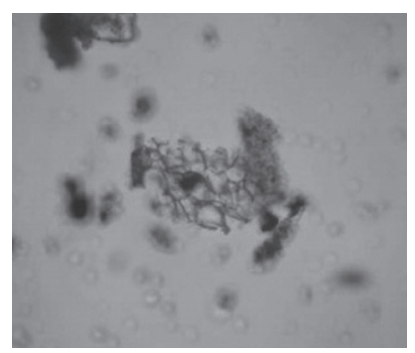

C) Labranza, Hornillo

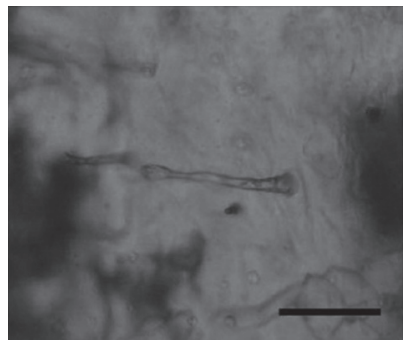

B) Tricoma Nicotiana acuminata

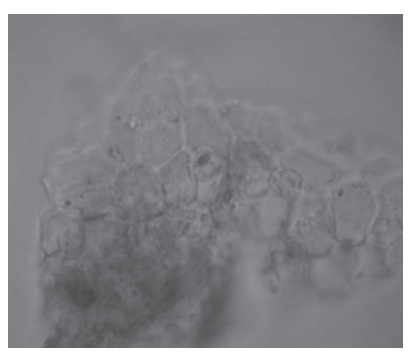

D) Células parenquimáticas

Nicotiana spp.

Figura 5: A a D: Microfósiles arqueológicos de tabaco nativo comparadas a los microfósiles registradas en la colección de referencia: A) Silicofitolito acicular articulado, tricoma, simil Nicotiana spp. B) Tricoma de Nicotiana acuminata (Planella et al. 2009), C) conjunto de células parenquimáticas. D) conjunto de células parenquimáticas de Nicotiana sp. (Planella et al. 2009). Escala de 20 $\mu$. Figure 5: A to D. Archaeological microfossils of native Tabaco compared to reference collection microfossils of Nicotiana sp.: A) Articulated aciculated phytolith, simil Nicotiana spp., B) Nicotiana acuminata trichome (Planella et al. 2009), C) group of parenchymatic cells., D) group of parenchymatic cells of Nicotiana sp. (Planella et al. 2009). Scale $20 \mu$.

En el cono sur de América, Pérez de Micou (1991) pone a prueba la proposición de Harstof (1988) y otros autores (Harris y Hillmann 1989), a través de la observación etnográfica y experimentación con recursos vegetales comestibles, medicinales y de uso tecnológico, con el fin de evaluar la visibilidad de las plantas y sus partes anatómicas en los registros 
arqueológicos de la Patagonia. Revela que el patrón de actividad en cada etapa de la secuencia operativa generará más o menos rastros directos (partes descartadas) e indirectos (residuos en instrumentos) ${ }^{4}$, siendo las tecnofacturas eminentemente visibles, de acuerdo a esos criterios. Recientemente, otros autores han aplicado el enfoque agronómico de la post-colecta o "postharvest" a la arqueobotánica, dando un nuevo giro al entendimiento de las cadenas operativas, mediante la integración de las tres esferas de prácticas - precolecta, colecta y postcolecta- referidas al uso de recursos vegetales, y enfatizando la importancia de la influencia de cada una de estas etapas sobre las que las preceden o suceden (Wollstonecroft et al.2009, Capparelli y Lema 2010, López 2010, Capparelli et al. 2011, Capparelli y Lema 2011). De esta manera, se amplía la conceptualización de la cadena operativa, por cierto basada en datos etnográficos o en su defecto etnohistóricos, hacia un modelo explicativo que permita identificar analíticamente las relaciones mantenidas entre cada una de las etapas mencionadas y el consumo, y a su vez evaluar su consecuencia para la lectura de los contextos arqueológicos, en tanto se generan patrones específicos de depositación en cada uno de los casos (Wollstonecroft et al.2009,Capparelli y Lema 2010,López 2010,Capparelli et al. 2011,Capparelli y Lema 2011).

El consumo de tabaco constituye una especificidad de uso de recursos vegetales en la que estos modelos conceptuales aportan ciertamente a su visibilidad en los contextos arqueológicos. No obstante, en calidad de sustancia psico-activa, el uso y/o consumo de tabaco puede extenderse a otras esferas de la vida social y conformar un subsistema de considerable complejidad cuya particularidad esperamos, en este trabajo, explicitar inicialmente a través la proposición de un modelo de cadena operativa. Antes de enunciarlo, ha de mencionarse la dificultad hasta ahora experimentada en pesquisar correlativamente contextos y artefactos asociados en torno al acto de fumar en pipas, ya que los estudios tradicionalmente realizados en la región para abordar la cuestión de los complejos de sustancias psicoactivas, han descansado en estudios químicos, no siempre concluyentes (Hairfield y Hairfield 2002, Muñoz y Peña 2009). En este sentido los estudios arqueobotánicos de pipas en contexto, que han incorporado las técnicas químicas de espectrometría/cromatografía de gases y estudios de sustancias adheridas, han demostrado ser una vía de resolución en cuanto a la determinación y caracterización de sus contenidos (Capparelli et al. 2006,Andreoni 2010). A través del estudio de microrrestos y residuos adheridos en las pipas de tres sitios arqueológicos de la región centro-sur de Chile, aquí presentados, y el caso específico de las pipas de JMC1-Labranza (Quiroz et al. 2011) hemos obtenido resultados que connotan la prevalencia 
de variados contextos y dispositivos desplegados vinculados a la actividad de fumar que pueda sintetizarse en la definición enriquecida del Complejo Fumatorio en la región central de Chile anteriormente formulado (Planella et al. 2000, Falabella et al.2001).

Los criterios que sustentan nuestra propuesta de modelo operacional se han recabado de la información etnográfica y etnohistórica consultada en fuentes escritas y de su fichaje correspondiente. La lectura analítica de estos documentos se efectuó a través de una ficha tipo que distingue distintas secciones temáticas de registro (Estévez 2011). Con ello se ha buscado obtener información que permita correlacionar distintos aspectos de los ámbitos de actividad vinculados al acto de fumar.

A modo de premisa se plantea que el uso de tabaco compartido por las poblaciones del período Alfarero Temprano de Chile semiárido y centro-sur modelaría las relaciones entre estos grupos, en la medida que ellos se diferencian identitariamente a través de particulares pautas socio- culturales, y de acuerdo al acceso a recursos específicos en un territorio, lo que se expresaría en las modalidades de obtención, selección, tratamiento y procesamiento y las ocasiones de consumo. De la secuencia de actividades graficadas en Figura 6, se entiende que la obtenciónes el modo de acceder a los recursos mediante su recolección, producción o intercambio; la selección se sustenta tanto en la acumulación de experiencia y el manejo discriminatorio de mitos y tabúes que influyen en la percepción del entorno, como en la disponibilidad de los recursos según la distribución vegetacional en el territorio y su estacionalidad. El tratamiento y/o procesamiento de los recursos (secado, colgado, molienda, tostado, almacenamiento) aplicados con los objetivos de promover efectos buscados y conservar propiedades específicas, depende de la finalidad perseguida según el contexto de uso. 


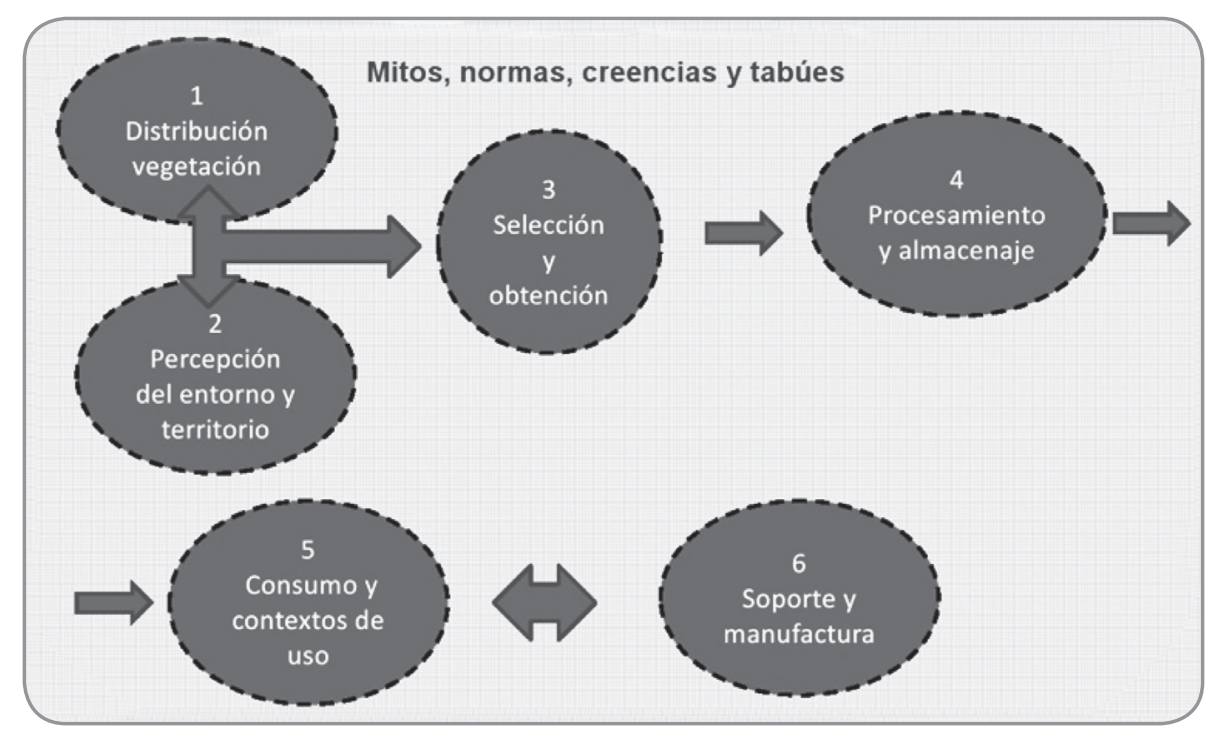

Figura 6: Propuesta de cadena operativa para el estudio de un Complejo Fumatorio.

Figure 6: Operative chain proposal for the study of a Smoking Complex.

Las ocasiones sociales de consumo tienen múltiples manifestaciones, en ellas confluyen los distintos ámbitos graficados en la Figura 6, y se relacionarían con la secuencia y expresión material y espacial del rito. En las ocasiones sociales y rituales de consumo de sustancias con componentes psicoactivos, se suscitaría la presencia de elementos adicionales, aromatizantes u otras, o mezclas de ellas, traduciendo particularidades en los modos de seleccionar y pautar los efectos perseguidos en la actividad y sentido del fumar. Al mismo tiempo, todos estos aspectos de la dinámica social de este diagrama de flujo subyacen a la imagen meramente formal de las pipas.

\section{Discusión}

El sitio de La Granja constituye un punto de partida desde el cual es posible proponer y agregar nuevos elementos de juicio para tratar el tema de la presencia de pipas en los yacimientos arqueológicos y el concepto de "Complejo Fumatorio" en las poblaciones del período Alfarero Temprano. Los atributos del sitio, con una alta concentración de fragmentos de pipas junto a estructuras construidas con bolones de río con particulares disposiciones espaciales y que incluyen entierros simbólicos de pipas, así como sus extensas dimensiones, sugieren entre otros elementos que era un lugar de congregación social y ritual (Planella 1988, Planella et al. 2000, Falabella 
et al. 2001, Castro y Adán 2001).La aplicación del estudio de residuos del contenido de pipas de La Granja por la vía química, arrojó resultados no concluyentes en relación a la procedencia de los alcaloides detectados, de tal manera que la introducción de los análisis de microfósiles entrega una nueva perspectiva de aproximación directa a resolver este problema.

En la muestra que integra este estudio, las pipas de La Granja-Bypass Rancagua sobresalen por su número, y luego por la mayor frecuencia de almidones en los tubos/boquillas; revelándose éstos como un rico material de investigación en lo que respecta a los residuos adheridos y por ende su potencial para determinar la presencia de las especies vegetales utilizadas y de los procesamientos a las que fueron sometidas. Las otras muestras (pipas de Pichicavén y JMC1-Labranza), aunque menos numerosas, mantienen un perfil similar a las anteriores, en cuanto a la menor frecuencia de almidones en los hornillos por la exposición directa al calor, y a la predominancia cuantitativa de fitolitos, desde luego teniendo en cuenta la diferente cantidad de muestras disponibles para cada sitio. Pese a ello, es destacable en el sitio Pichicavén, la mayor frecuencia de fitolitos en el hornillo ( $n=57)$ y el bajo número de microfósiles en el tubo/boquilla. En el sitio de JMC1-Labranza en ambas pipas resalta la mayor cantidad de microfósiles en los tubo/boquillas (fitolitos, $\mathrm{n}=38$ y $\mathrm{n}=39$ y almidones, $\mathrm{n}=4$ y $\mathrm{n}=2$ ) versus lo que se detectó en los hornillos (fitolitos, $\mathrm{n}=24 \mathrm{y} \mathrm{n}=1$ ), almidones, $\mathrm{n}=1$ ). Asimismo, se observa que estos resultados presentan congruencia y escasa distancia numérica entre sí. Finalmente, el análisis de los sedimentos exhibió particularidades notorias como es la abundancia de cristales, fitolitos, presencia de polen y esferulitas y la ausencia de microcarbones, en comparación con los residuos de las pipas. Estas peculiaridades reflejan la condición natural de formación del sedimento depositado en las pipas y los probables usos posteriores del suelo para fines agropecuarios.

Por su parte, los resultados preliminares de determinación taxonómica permiten adelantar la presencia de almidones simil Nicotianaspp. en dos tubos de pipas del sitio La Granja-Bypass Rancagua y en los hornillos de las pipas de JMC1-Labranza y Pichicavén, en este último caso con huellas tafonómicas correspondientes a escasa birrefringencia. Estos resultados, por su recurrencia, auspician continuar con esta línea de investigación y cotejar la hipótesis de la significación del tabaco, mencionada en los estudios etnográficos consultados. En esta tarea es imprescindible disponer de un mayor número de muestras y contrastación con colecciones de referencia. 
Es precisamente la identificación de tabaco en estos contextos y su profusa alusión a su rol protagónico en las actividades rituales y cotidianas que nos lleva a considerar que existe una dinámica social que opera detrás de las evidencias de consumo de tabaco (pipas y sus contenidos). Consecuentemente, nuestros estudios apuntan hacia la reconstrucción de distintos aspectos del quehacer social cotidiano y/o ritual involucrado en la acción de fumar. Si bien el diagrama de flujo de la cadena operativa que se ha bosquejado presenta una visión general de las dinámicas implicadas desde la obtención de las materias primas hasta la finalidad última del consumo de las sustancias psicoactivas, todo ello bajo el marco de normas, creencias, mitos y tabúes de cada sociedad, es posible mostrar evidencias fragmentarias de segmentos de dicha cadena aportadas por este estudio. En el sitio JMC1Labranza, ciertos datos dan cuenta de actividades asimiladas probablemente a la etapa de consumo como lo son silico fitolitos simil Bambusioidea (Figura $4 \mathrm{H}$ ) en hornillo y tubo/boquilla de la pipa sin contexto, testigo de la posible utilización de varitas de coligüe (Chusquea culeou Desv.) para iniciar fuego y/o limpiar el conducto de la pipa (Guevara 1911, Guevara y Oyarzun 1912, Quiroz et al. 2011). Estas varitas son parte de una amplia gama de implementos de la parafernalia y conductas asociadas al consumo de tabaco, tal como lo registra la etnografía. Es posible realizar el mismo ejercicio a partir de la presencia de tricomas de Nicotiana spp., registrados en la pipa de JMC1-A y de Pichicavén que refieren el uso de las hojas de tabaco por sobre otras partes de la planta. La presencia de almidones propios de semillas, hojas y raíces (pipas de La Granja, Pichicavén y JMC1-Labranza) y de tejido parenquimático ubicado en partes duras de hojas y tallos (pipa de JMC1-A), refuerzan la idea de que se seleccionaron preferentemente ciertas partes de la planta para su consumo.

Los análisis de microfósiles han aportando en la recuperación e identificación de restos arqueobotánicos en el contenido de las pipas, sin embargo es necesario, para mayores certezas, complementar esta visión fragmentaria con la integración de otros tipos de estudios, como lo son los análisis químicos. De esa forma se logra reducir el sesgo que conlleva la recuperación de microfósiles.

Finalmente es importante destacar que las similitudes de los contenidos de las pipas, refrendada por la presencia de tabaco, ocurren a pesar de sus diferencias morfológicas, su adscripción a distintos grupos culturales, y la distancia espacial de su procedencia. Por consiguiente, la recurrencia del hallazgo de tabaco en estos contextos pone en evidencia el carácter articulador de esta planta psicoactiva a través de su participación en la dinámica de un sistema social dentro del cual el Complejo Fumatorio es 
uno de los mecanismos de cohesión y reforzamiento identitario. En último término, nos parece fundamental medir su alcance cultural en las sociedades del período Alfarero Temprano que se caracterizan por cambios importantes en la estructura social y las formas de subsistencia.

Agradecimientos: Este estudio se desarrolló con el apoyo de los proyectos Cooperación Internacional 7050165, Fondecyt 1080360 y FONDART 21511-2. En especial se agradece a Carmen del Rio, Directora del Museo Regional de Rancagua quien facilitó la colección de pipas del Bypass Rancagua, a Blanca Tagle, Pilar Rivas, Andrés Troncoso, Rodrigo Mera y Doina Munita por su interés y apoyo en esta investigación. Extendemos nuestros agradecimientos a Eugenio Aspillaga, quien facilitó el uso de las instalaciones del Laboratorio de Antropología Física del Depto. de Antropología, Universidad de Chile. Agradecemos la acogida de Álvaro Villagrán y Roxana Seguel en el Laboratorio de Análisis del Centro Nacional de Conservación y Restauración; de Hermann Niemeyer en el Depto. de Ciencias Ecológicas, Facultad de Ciencias, Universidad de Chile y del Departamento Geología, Facultad de Ciencias Físicas y Matemáticas de la Universidad de Chile.

\section{Notas}

1 Algunos de los autores citados efectúan una adscripción taxonómica asignándola a una de las especies de Nicotiana existente en Chile.

2 Corresponden a plantas pertenecientes a las Angiospermas, cuyos tallos pueden ser herbáceos o leñosos (Teillier 1998:18).

3 Se ha preferido usar la denominación Nicotianaspp. hasta completar la colección de referencia de almidones de tabacos nativos disponibles.

4 No obstante, a nuestro juico los residuos en instrumentos constituyen una evidencia directa del uso de los recursos vegetales.

5 Por cierto, es importante considerar la esfera de producción y todo lo que de ello implica al formar parte del Complejo Fumatorio

\section{BIBLIOGRAFÍA}

Aldunate, C. 2002-2003."Perrimontuelawen. Plantas visionarias de los Mapuche (Chile)”. Eleusis 6-7: 103-126.

Andreoni, D. 2010."Propuesta metodológica para reconocer las prácticas asociadas al uso de las pipas arqueológicas". Actas del XVII Congreso Nacional de Arqueología Argentina, tomo III: 1211-1216.Mendoza, Argentina.

Babot, M.P. 2003.“Starch grain damage as an indicator of food processing”. En Phytolith and starch research in the Australian-Pacific-Asian regions: the state of the art, editado por D. Hart y L. Wallis, pp: 69-81. Pandamus Books for the Centre for Archaeological Research, Canberra. 
----- 2004. Tecnología y utilización de artefactos de molienda en el Noroeste prehispánico.(Ms) Tesis para optar al grado de Doctor en Arqueología, Facultad de Ciencias Naturales e IML, Universidad Nacional de Tucumán. San Miguel de Tucumán.

Babot, M.P., P. Escola y S. Hocsman. 2008. "Microfósiles y atributos tecnotipológicos: correlacionando raederas de módulo grandísimo con sus desechos de talla de mantenimiento en el Noroeste Argentino". EnMatices Interdisciplinarios en Estudios Fitoliticos y de Otros Microfósiles, editado por A. Korstanje y M.P. Babot, pp: 187-200. British Archaeological Reports, Oxford.

Barton, H., R. Torrence y R. Fullagar. 1998. "Clues to stone tools function reexamined: comparing starch grain frequencies on used and unused obsidian artifacts". Journal of Archaeological Science 25: 1231-1238.

Berenguer, J. 2001. "Evidence for snuffing and shamanism in prehispanic Tiwanaku stone sculpture". Eleusis 5:61-84.

Briuer, F. 1976. "New clues to stone tool functions: plants and animal residues". American Antiquity 41(4):478-484.

Capparelli, A. y V. Lema. 2010. "Practica post-colecta/post-aprovisionamiento de recursos vegetales: una perspectiva paleoetnobotánica integradora aplicada a casos de argentina". Actas del XVII Congreso Nacional de Arqueología Argentina, tomo III: 1171-1176. Mendoza, Argentina.

-----2011. "Recognition of post-harvest processing of algarrobo (Prosopis spp.) as food from two sites of North-western Argentina: an ethnobotanical and experimental approach for desecated macroremains". Archaeological Anthropological Science 3:71-92.

Capparelli, A., M. Pochettino; A. Diego y R. Iturriza. 2006. "Differences between written and archaeological record: The case of plant micro remains recovered at a Northwestern Argentinean Pipe". En Proccedings of the IV International Congress of Ethnobotany (ICEB 2005), editadopor Z. Fusun Ertu, pp: 397-406. Zero Prod. Ltd., Estambul.

Capparelli, A., S.Valamoti y M. Wollstonecroft. 2011. "After the harvest: investigating the role of food processing in past human societies". Archaeological Anthropological Science 3:1-5.

Castro, V.yA. Leonor. 2001.“Abriendo diálogos. Una mirada entre la etnohistoria y la arqueología del Área Centro Sur de Chile: Asentamientos en la Zona Mapuche”. Revista Werkén 2:5-35. 
Chacama, J. 2001. "Tabletas, tubos y espátulas. Aproximación a un complejo alucinógeno en el área de Arica, extremo norte de Chile". Eleusis 5: 85-100.

Ciprés Consultores 2002. Informe final: proyecto plan de rescate y evaluación del patrimonio arqueológico Enlace Rancagua, Bypass Rancagua. Manuscrito en posesión de los autores.

Citarella, L., A. Conejeros, B. Espinossa, I. Jelves, A.Oyarce, y A. Vidal. 1995. Medicinas y Culturas en La Araucanía. Editorial Sudamericana, Santiago.

Coil, J., A. Korstanje, S. Archer y C. Harstof. 2003. "Laboratory goals and considerations for multiple microfossil extraction in archaeology". Journal of Archaeological Science 30: 991-1008.

Cooper, J. 1949."Stimulants and Narcotics".En Handbook of South American Indians 5, editado porJ. H. Steward, pp:525-558. Smithsonian Institution, Washington.

Cornely, F. 1966.Cultura Diaguita y Cultura de El Molle. Editorial del Pacífico S. A., Santiago.

Dennell, R. 1976. "The economic importance of plant resources represented on archaeological sites". Journal of Archaeological Science 3:229-248.

Dougherty, B. 1972. "Las pipas de fumar arqueológicas de la Provincia de Jujuy". Relaciones de la Sociedad Argentina de Antropología VI: 83-89.

Eliade, M. 1960.El Chamanismo y las Técnicas Arcaicas del Éxtasis. Fondo de Cultura Económica, México.

Erize, E. 1987.Mapuche 1. Editorial Yepun, Buenos Aires.

Estévez, D. 2011. Fichas Bibliográficas para el Estudio de Pipas prehispanas y sus contextos. Manuscrito en posesión de las autoras.

Falabella, F., M.T. Planella y B. Tagle. 2001."Pipes and smoking tradition in the prehispanic societies of the early ceramic period of the central region of Chile". Eleusis 5: 137-151.

Faron, L. 1961.MapucheSocial Structure. University of Illinois Press, Illinois.

-----1964. Hawks of the Sun. Mapuche Morality and its Ritual Attributes. University of Pittsburgh Press, Pittsburg.

Fernández Distel, A. 1980. "Hallazgos de pipas en complejos precerámicos del borde de la Puna jujeña (República Argentina) y el empleo de alucinógenos por parte de las mismas culturas". Estudios Arqueológicos 5:55-75. 
Fernández Distel, A., M. Raviña y B. Balesta. 1999. Las Pipas Precolombinas del Norte Argentino.Academia Nacional de la Historia, Buenos Aires.

Föerster, R. 1995. Introducción a la Religiosidad Mapuche. Editorial Universitaria, Santiago.

Föerster, R. y H. Gundermann. 1996. "Religiosidad Mapuche contemporánea: elementos introductorios". En: Etnografía, sociedades indigenas contemporáneas y su ideología, editado por J. Hidalgo, V. Schiappacasse, H. Niemeyer, C. Aldunate y P. Mege, pp: 189-240. Editorial Andrés Bello, Santiago.

Fullagar, R., Furby, J. y B. Hardy. 1996. "Residues on stone artefacts: state of a scientific art”. Antiquity 70:740-745

Guevara, T. 1911. Folklore Araucano: Refranes, Cuentos, Cantos, Procedimientos Industriales, Costumbres Prehispanas. Imprenta Cervantes, Santiago.

Guevara, T. y A. Oyarzún. 1912."El tabaco y las pipas prehistóricas de Chile”. Actas del XVII Congreso Internacional de Americanistas, pp: 414-437. Buenos Aires, Argentina.

Gusinde, M.1917. "Medicina e higiene entre los antiguos araucanos". Revista Chilena de Historia y Geografía 22: 385-412.

Haberman, T. W. 1984."Evidence for aboriginal tobaccos in eastern North America”. American Antiquity 49(2): 269-287.

Hairfield, H.y E. Hairfield. 2002. "Smoking out the Past. Anthropology uses GC-MS to determine the botanical origins of residue in ancient clay pipes from Chile". Today's Chemist at work: 27-31.

Harris, D. y G. Hillman (editores).1989. Foraging and Farming: The Evolution of Plant Explotation. Unwin Hyman, Londres.

Hastorf, C. 1988. "The use of Paleoethnobotanical data in prehistoric studies of crop production, processing and consumption”. En Current Paleoethnobotany, Analytical methods and cultural interpretations of archaeological plant remains, editado por C. Harstof y V. Popper, pp: 119-144. University Press, Chicago.

Hermosilla, N. 2001. "The people of the tumi, the condor and the jaguar: Psychoactive plant use in the Loa river basin, Atacama Desert". Eleusis 5: 123-136.

Hilger, M. 1957.Araucanian Child Life and its Cultural Backgrounds. Smithsonian Institution, Washington.

Housse, E. 1940.Una Epopeya India. Editorial Zig-Zag, Santiago. 
ICPN Working Group: Madella, M., A. Alexandre y T. Ball. 2005. "International code for phytolith nomenclature 1.0". Annals of Botany 96(2):253-260.

Kealhofer, L., R. Torrence y R. Fullagar. 1999. "Intergrating phytoliths within use-wear/residues studies of stone tools". Journal of Archaeological Science 26: 527-546.

Korstanje, M.A. 2009. "Microfósiles y agricultura prehispánica: primeros resultados de un análisis múltiple en el Noroeste Argentino". En Fitolitos: estado actual de sus conocimientos en América del Sur, editado por A. Zucol, M. Osterrieth y M. Brea, pp: 249 - 263. Universidad Nacional de Mar del Plata, Mar del Plata.

Korstanje, M. A. y M. P. Babot. 2007. "A microfossil characterization from South Andean economic plants". En Plants, people and places: recent studies in phytholithic analysis, editado por M. Madela y D, Zurro, pp: 41-72. OxbowBooks, Cambridge.

Lagiglia, H. 1992. "Pipas de fumar indígenas de Mendoza y Neuquén, con un aporte al conocimiento de los narcotizantes y alucinógenos americanos". Revista del Museo de Historia natural de San Rafael 11(4): 201-216.

Latcham, R. 1924. "La organización social y las creencias religiosas de los antiguos Araucanos". Publicaciones del Museo de Etnología y Antropología $3(2-4): 245-868$.

----- 1936.La Agricultura Precolombiana en Chile y los Países Vecinos. Ediciones de la Universidad de Chile.

Llagostera, A. 2001. "Archaeology of hallucinogens in San Pedro de Atacama". Eleusis 5: 101-121.

Loy, T. 1994. "Methods in the analysis of starch residues on prehistoric stone tools". En Tropical Archaeobotany: applications and new development, editado por J.Hather, pp: 86-114. Routledge, New York.

Loy, T. y R. Fullagar. 2006. "Box 9.8. Residue Extraction”. En Ancient Starch Research, editado por R. Torrence y H. Barton, pp: 197-198. Left Coast Press, California.

López, M. 2010. "Desgranando las panojas: aproximación etnobotánica y etnoarqueológica del el procesamiento de quínoa en NorLipez, Potosi, Bolivia". Actas del XVII Congreso Nacional de Arqueología Argentina, tomo III:1177-1181. Mendoza, Argentina.

Medina, J. 1898.Los Aborígenes de Chile. Imprenta Universitaria, Santiago. 
Mera, R. y D. Munita. 2008. Informe Ejecutivo Salvataje Sitio Villa JMC-01, Labranza, Provincia de Cautín, Región de La Araucania. Manuscrito en posesión de los autores.

Molina, J. [1788] 2000.Compendio de la Historia Geográfica, Natural y Civil del Reyno de Chile. Pehuén Editores, Chile.

Muñoz, O. y R. Peña. 2009.“Investigaciones recientes en la determinación de residuos de pipas arqueológicas de Chile central". Boletin del Museo Nacional de Historia Natural 58: 83-89.

Niemeyer, H., G. Castillo y M. Cervellino. 1989.“Los primeros ceramistas del Norte Chico: Complejo El Molle (0-800 d.C.)”. En Prehistoria. desde sus origenes hasta los albores de la Conquista, editado por J. Hidalgo, V. Schiappacasse, H. Niemeyer, C. Aldunate e I. Solimano, pp: 227-263. Editorial Andrés Bello, Santiago.

Niemeyer, H., M. Cervellino y G. Castillo (editores). 1998. Culturas Prehistóricas de Copiapó. Museo Regional de Atacama, Copiapó.

Núñez de Pineda y Bascuñán, F. 1984 [1663]. Suma y Epilogo de lo más esencial que contiene el libro intitulado Cautiverio Feliz, y Guerras dilatadas del Reino de Chile. Sociedad Chilena de Historia y Geografía. Ediciones Universidad Católica, Stgo.

Olivos, C. 2004."Plantas psicoactivas de eficacia simbólica: indagaciones en la herbolaria mapuche”. Chungará36(2):997-1014.

Ovalle, A. De [1646] 1969. Histórica Relación del Reyno de Chile. Instituto de Literatura Chilena, Santiago.

Parr, J., C. Lentfer y W. Boyd. 2001. "A comparative analysis of wet and dry ashing techniques for the extraction of phytoliths from plant material". Journal of Archaeological Science 28:875-886.

Pérez de Micou, C. 1991. "Secuencias operativas de artefactos y ecofactos vegetales.Su variabilidad en el registro arqueológico". Actas del XI Congreso Nacional de Arqueología Chilena, tomo 3: 201-215. Santiago, Chile.

Pérez Gollán e I. Gordillo. 1994. "Vilca/Uturuncu. Hacia una arqueología del uso de alucinógenos en las sociedades prehispánicas de los Andes del Sur". Cuicuilco 1: 99-140.

Planella, M.T. 1988. La propiedad territorial indigena en la cuenca de Rancagua, siglos XVI y XVII. Tesis para optar al título de Magister en Historia, mención Etnohistoria, Departamento de Ciencias Históricas, Universidad de Chile. 
Planella, M.T., F. Falabella y B. Tagle. 2000. "Complejo fumatorio del período Alfarero Temprano en Chile central”. Contribución Arqueológica 5(I):895909

Planella, M.T., R. Peña, F. Falabella y V. McRostie. 2005-2006."Búsqueda de nexos entre prácticas funerarias del período Alfarero Temprano del centro de Chile y usos etnográficos del miyaye". Historia Indígena9: 33-49.

Planella, M.T., L. Quiroz, C. Belmar y V. McRostie. 2009. "Explorando el bosque esclerófilo: fitolitos y almidones de la flora nativa de Chile central". Libro de resúmenes del XVIII Congreso Nacional de Arqueología Chile, pp: 201-203. Gráfica LOM, Valparaíso.

Pollard, A., C. Batt, B. Stern y S. Young. 2007. Analytical chemistry in archaeology. Cambridge University Press, New York.

Rosales, D. 1877-78. Historia General del Reino de Chile. Flandes Indiano. Imprenta de El Mercurio, Valparaíso.

Quiroz, D. y M. Sánchez. 2005. "La secuencia Pitrén-El Vergel en Isla Mocha: soluciones de continuidad y distinciones culturales". En: Actas del XVI Congreso Nacional de Arqueología Chilena, pp: 369-378. Escaparate Ediciones, Concepción.

Quiroz, L., C. Belmar, M.T. Planella, R. Mera y D. Munita. 2011. "Estudio de microfósiles de residuos adheridos en pipas cerámicas del sitio JMC1 Labranza, Región de la Araucanía". Enviado a publicación en Revista Magallania.

Reichert, E. 1913. The differentiation and specificity of starches in relation to Genera, Species, Etc. Carnegie Institution of Washington, Washington D.C.

Reyes, V., L. Sanhueza y L. Adán. 2003-2004. "Alfarería doméstica y funeraria de la Región del Calafquén”. Revista Chilena de Antropología 17: 151-179.

Rots, V. y B. Williamson. 2004. "Microwear and residue analyses in perspective: the contribution of ethnoarchaeological evidence". Journal of Archaeological Science 31: 1287-1299.

Schultes, R. y A. Hofmann. 1979. Plants of the Gods: Origins of Hallucinogenic Use. McGraw-Hill, New York.

Serrano, A. 1934."El uso del tabaco y vegetales narcotizantes entre los indígenas de América”. Revista Geográfica Americana II(15):415-425.

Teiller, S., H. Zepeda y P. Garcia. 1998. Flores del desierto de Chile. Marisa Cuneo Ediciones, Valdivia. 
Torres, C. 1998. "Psychoactive substances in the archaeology of Northern Chile and NWArgentina".Chungara30(1): 49-63

---- 2001. "Shamanic Inebriants in South American Archaeology: Recent Investigations". Eleusis5:3-12.

Troncoso, A. 2010. Forma, Estilo y Espacio en el arte rupestre de los valles de Illapel y Chalinga. Informe $3^{\circ}$ año FONDECYT 1080360. Conicyt, Santiago.

Valdivia, P. De. 1960 [1545]. "Cartas al Emperador Carlos V”. En Crónicas del Reino de Chile, Tomo 131: 1-74.Ediciones Atlas, Madrid.

Vivar, G. De 1979 [1558].Crónica y relación copiosa y verdadera de los Reinos de Chile. Colloquium Verlag, Berlin.

Westfall, C. 1993-1994. "Pipas prehispánicas de Chile. Discusión en torno a su distribución y contexto”. Revista Chilena de Antropología 12: 123-161.

Wilbert, J. 1987.Tobacco and shamanism in South America. Yale University Press, New York.

Wollstonecroft, M., T. Valamoti y A. Capparelli. 2009. "Recent research in post-harvest traditions in human prehistory: Old and New World palaeoethnobotanical approaches to linking the archaeology and ethnobotany of plant processing". Trabajo presentado enV International Congress of Ethnobotany: traditions and transformations in ethnobotany, 21 al 24 de septiembre de 2009. San Carlos de Bariloche, Argentina. (disponible en http://www.iceb09.blogspot.com) 